\title{
Role of Fine Needle Aspiration Cytology in Male Breast Lesions
}

\author{
Mohanvir Kaur¹, Deepika Wadhera², Ramesh Kumar Kundal ${ }^{3}$, Chettan Dass ${ }^{4}$, \\ Ninder Kumar Mall5, Kanwardeep Kaur Tiwana ${ }^{6}$
}

${ }^{1}$ Department of Pathology, GMC, Patiala, Punjab, India. ${ }^{2}$ Department of Pathology, GMC, Patiala, Punjab, India. ${ }^{3}$ Department of Pathology, GMC, Patiala, Punjab, India. ${ }^{4}$ Department of Pathology, GMC, Patiala, Punjab, India. ${ }^{5}$ Department of Pathology, GMC, Patiala, Punjab, India. ${ }^{6}$ Department of Pathology, GMC, Patiala, Punjab, India.

\section{ABSTRACT}

\section{BACKGROUND}

Fine Needle Aspiration (FNA) is a well-established and widely accepted procedure in the evaluation of breast masses. Fine needle aspiration cytology can be performed as an OPD procedure. It is less traumatic to the patient as compared to surgical biopsy, is cost effective, and can provide rapid results on the same day. Therefore, it can be used as an initial diagnostic procedure for male breast lesions. The aim of our study was to determine the efficacy of Fine-Needle Aspiration Cytology (FNAC) in the diagnosis of male breast lesions and categorization of these lesions as per IAC Categories.

\section{METHODS}

The present study included 50 cases of male breast lesions presented in the department of the pathology. Fine-Needle Aspiration Cytology (FNAC) was done and slides were stained with MGG and PAP. Findings were analysed by two pathologists independently. Cyto-histological correlation was done in cases wherever possible. Sensitivity and specificity were calculated.

\section{RESULTS}

A total of 50 cases of male breast lesions which had undergone FNAC was analysed in this study. Histopathological examination was available in 10 cases. Gynecomastia C2 (88\%) was found to be the most common entity followed by acute on chronic suppurative pathology $(4 \%)$. There was no false positive or false negative finding. FNAC had a sensitivity and specificity and diagnostic accuracy of $100 \%$ for male breast lesions.

\section{CONCLUSIONS}

FNAC is the excellent sensitive and specific diagnostic tool for the assessment of breast lesions in males. Hence, we strongly recommend the use of FNAC as the firstline investigation in the clinical evaluation of male breast lumps.
Corresponding Author: Dr. Deepika Wadhera, Postgraduate Resident, Department of Pathology, Government Medical College, Patiala, Punjab, India. E-mail: deepika01280@gmail.com

DOI: $10.14260 /$ jemds/2020/330

Financial or Other Competing Interests: None.

How to Cite This Article:

Kaur M, Wadhera D, Kundal RK, et al. Role of fine needle aspiration cytology in male breast lesions. J. Evolution Med. Dent. Sci. 2020;9(18):1515-1518, 10.14260/jemds/2020/330

Submission 21-01-2020, Peer Review 16-04-2020, Acceptance 23-04-2020, Published 04-05-2020.

\section{KEY WORDS}

FNAC, Male Breast, Gynecomastia 


\section{BACKGROUND}

In this modern era, as the medical facilities and diagnostic methods are so advanced, still Fine-Needle Aspiration Cytology (FNAC) play a major role in the diagnosis of breast lesions in a developing country.[1] The Fine-Needle Aspiration Cytology (FNAC) was first introduced by the Martin and Ellis in 1930.[2] Fine needle aspiration cytology can be performed as an OPD procedure. It is less traumatic to the patient as compared to surgical biopsy, is cost effective and can provide rapid results on the same day.[3] Therefore it can be used as initial diagnostic procedure for male breast lesions. In combination with mammography or ultrasonography and clinical examination, Fine-Needle Aspiration (FNA) forms a diagnostic triad, which has approximately $100 \%$ accuracy. ${ }^{[4]}$ Fine needle aspiration has become widely accepted as a reliable diagnostic tool with high sensitivity and specificity and with a minimal rate of complications. ${ }^{[5]}$ Gynecomastia is the most frequently encountered cause of benign masses in male breast and carcinoma of the male breast is rarely documented.[6,7] It is related to increase in the oestrogen levels and reduced androgenic hormone level which lead to hyperplasia and hypertrophy of the ductal and stromal component of breast. The various pathological causes of gynecomastia are liver cirrhosis, hyperthyroidism, renal failure, chronic lung disease, germ cell tumour and various drugs like spironolactone, digitalis, cimetidine etc. Gynecomastia can be clinically seen behind the nipple whereas the breast carcinoma is located eccentrically in males. It is unilateral in most of the cases but in puberty and hormone induced it may be bilateral.[8] Breast cancer in men is relatively uncommon, accounting for $<1 \%$ of all breast cancers and $<1.5 \%$ of all the malignancy in men.[9]

The incidence of carcinoma breast is seen in elderly male. Klinefelter syndrome is associated with increased risk of male breast carcinoma. In prostate cancer when we give oestrogen therapy to the patient, sometimes it may lead to breast carcinoma. Similar to the female breast carcinoma if male presented with bloody nipple discharge it is highly suspicious for carcinoma breast.[10] Other lesions in the male breast which are extremely rare and include fibroepithelial tumours, Duct ectasia, papilloma and fibrocystic change.[11] Although screening, early and presumptive diagnosis with proper management improves the outcome but male patients often presented in advance stage resulting in higher morbidity and mortality which is probably due to lack of awareness, unestablished early screening method and paucity of the research on this topic.[12]

The International Academy of Cytology (IAC) gathered together a group of cytopathologists, expert in breast cytology and developed in 2016, the IAC Yokohama system for reporting breast Fine Needle Aspiration Biopsy (FNAB) cytology. The system defines five categories for reporting Breast cytology: C1- Insufficient/ Inadequate, C2- Benign, C3Atypical, C4- Suspicious of malignancy and C5-Malignant. [13] The aim of our study was to determine the efficacy of Fine needle aspiration cytology in the diagnosis of male breast lesions and also we attempted to describe the cytomorphologic features of a few of the lesions encountered in our series.
We wanted to determine the efficacy of FNAC in the diagnosis of male breast lesions and categorize these lesions as per IAC Categories.

\section{METHODS}

The retrospective study was done in the Department of Pathology, Government Medical College, Patiala. Fine-Needle Aspiration Cytology (FNAC) was done on the male patients with breast lesions. After explaining complete procedure, written informed consent was obtained from the patient. All aspirates were performed in the outpatient department using 23-gauge needle and $10 \mathrm{ml}$ syringe. Air dried smears were prepared and stained by the May-Grunwald-Giemsa stain and smears were wet-fixed in 95\% ethyl alcohol and subsequently stained with Papanicolaou stain as well as Haematoxylin and Eosin ( $\mathrm{H} \& \mathrm{E}$ ) stain and examined under microscope. The stained smears were classified into one of five categories, these being C1 (non-diagnostic), C2 (benign), C3 (atypical), C4 (suspicious) and C5 (malignant). Histopathologic diagnosis was obtained wherever available and the cytologic diagnosis was retrospectively correlated with histologic findings. Finally sensitivity and specificity was calculated. The study was approved by Ethics Committee.

\section{Statistical Analysis}

The data was compiled using MS Excel. Sensitivity and specificity was calculated.

\section{RESULTS}

This is the 2 year study in which, 50 male patients with palpable breast lumps underwent Fine-Needle Aspiration Cytology (FNAC). Of these, 45 presented with unilateral breast lumps (90\%) and 5 had bilateral breast lumps (10\%). Wide range of age was seen ranging from 14 to 81 years. The distribution of lesions was C1 (nondiagnostic) 2\%, C2 (benign) 92\%, C3 (atypical) 2\%, C4 (suspicious) 2\% and C5 (malignant) 2\%. There were no false positive or false negative diagnoses. FNAC had a sensitivity, specificity and diagnostic accuracy of $100 \%$ for male breast lesions.

\begin{tabular}{|l|c|c|c|}
\hline \multicolumn{2}{|c|}{ Categories } & Cytological Finding & No. \\
\hline C1 & $\begin{array}{c}\text { Non- } \\
\text { diagnostic/unsatisfactory }\end{array}$ & Acellular & $1(2 \%)$ \\
\hline \multirow{2}{*}{ C2 } & Benign & Gynecomastia & $44(88 \%)$ \\
\cline { 3 - 4 } & Atypical & $\begin{array}{c}\text { Acute on chronic suppurative } \\
\text { pathology }\end{array}$ & $2(4 \%)$ \\
\hline C3 & Suspicious & Cytological Atypia & $1(2 \%)$ \\
\hline C5 & Malignant & Carcinoma suggestive of IDC Breast & $1(2 \%)$ \\
\hline \multicolumn{4}{|c|}{ Table 1. Cytological Finding of Male Breast Lesions } \\
\hline
\end{tabular}

\section{Cytomorphological Features of Male Breast Lesions in Our Study}

Most common cytomorphological entity in this study was gynecomastia $\mathrm{C} 2$. The smears revealed variable cellularity ranging from mild, moderate cellular (predominant pattern) to richly hyper-cellular smears. Smears revealed large, tightly 
cohesive ductal epithelial cell fragments, at times appearing as flat monolayered sheets. Also seen were many single, bare, bipolar/oval nuclei in background i.e. bimodal pattern. Fragments of fibrous stroma were commonly present. Out of 50 cases of male breast lesion the histopathological confirmation was done in 10 cases. Out of 44 cases of gynecomastia, histopathological confirmation was done in 8 cases (18.1\%). FNAC smear revealed many polymorphs, viable as well as degenerating admixed with few ductal epithelial cells. This was reported as inflammatory lesion and was managed with antibiotics.

On cytology, 1 case (2\%) was suspicious for malignancy and 1 case was suggestive of IDC breast, and histopathological confirmation was done in both the cases. The aspirates revealed loosely cohesive clumps and singly scattered cells showing nuclear enlargement with anisonucleosis, irregular nuclear borders and prominent nucleoli. On cytology, tumour cells were arranged in small and large clumps and also in linear fashion. The cells had round to oval nuclei with prominent one to four nucleoli. On histopathological examination, tumour cells with hyperchromatic, pleomorphic nuclei were seen.

\begin{tabular}{|c|c|c|c|c|c|}
\hline & Categories & $\begin{array}{l}\text { Cytological } \\
\text { Finding }\end{array}$ & No. & $\begin{array}{l}\text { Histopathological } \\
\text { Diagnosis }\end{array}$ & No. \\
\hline C1 & $\begin{array}{l}\text { Non-diagnostic/ } \\
\text { unsatisfactory }\end{array}$ & Acellular & $1(2 \%)$ & Not done & 0 \\
\hline \multirow[b]{2}{*}{$\mathrm{C} 2$} & \multirow[b]{2}{*}{ Benign } & Gynaecomastia & $\begin{array}{c}44 \\
(88 \%)\end{array}$ & Gynecomastia & 8 \\
\hline & & $\begin{array}{l}\text { Acute on chronic } \\
\text { suppurative pathology }\end{array}$ & $2(4 \%)$ & Not done & 0 \\
\hline C3 & Atypical & Cytological Atypia & 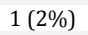 & & 0 \\
\hline $\mathrm{C} 4$ & Suspicious & Suspicious for malignancy & $1(2 \%)$ & IDC Breast & 1 \\
\hline \multirow[t]{2}{*}{$\mathrm{C} 5$} & Malignant & $\begin{array}{c}\text { Carcinoma suggestive of } \\
\text { IDC Breast }\end{array}$ & $1(2 \%)$ & IDC Breast & 1 \\
\hline & $M$ & $\begin{array}{l}\text { vtologic and Histo } \\
\text { Breast Lesions }(10\end{array}$ & teat & $\begin{array}{l}\text { egories of } \\
\text { ases) }\end{array}$ & \\
\hline
\end{tabular}

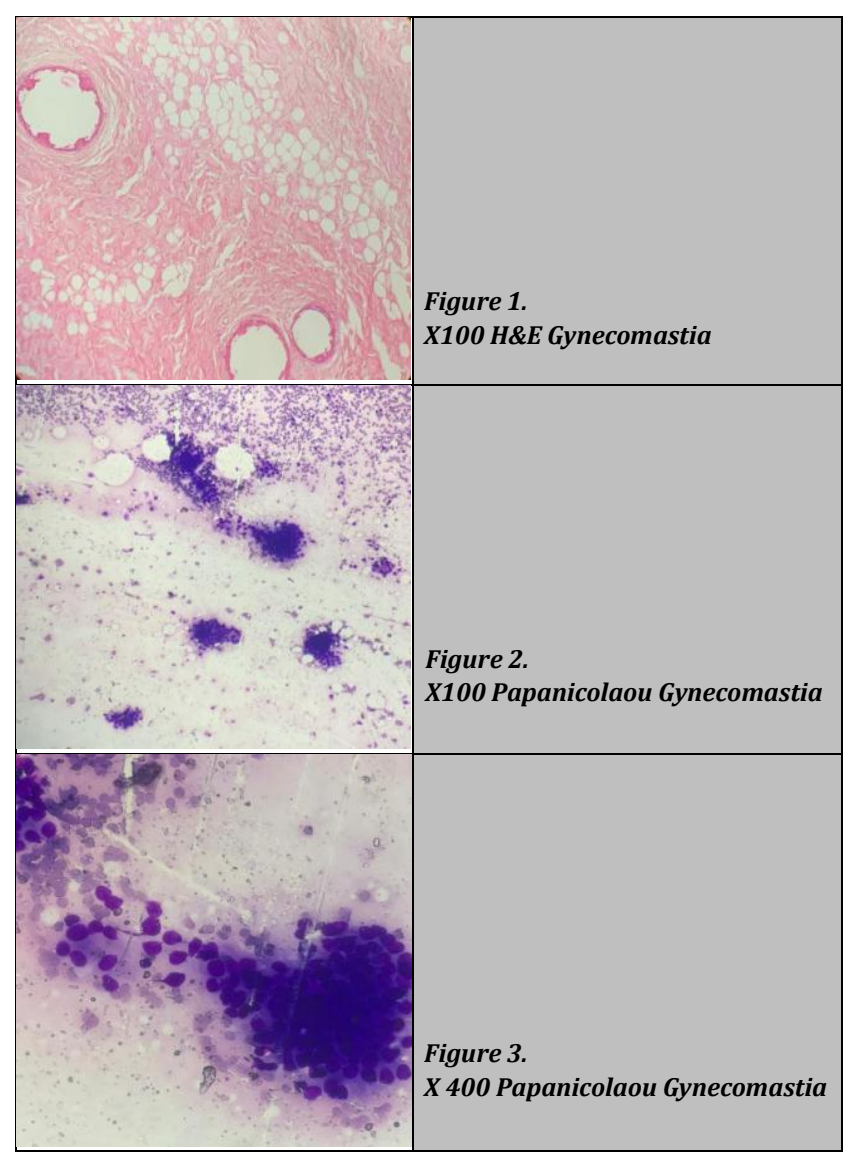

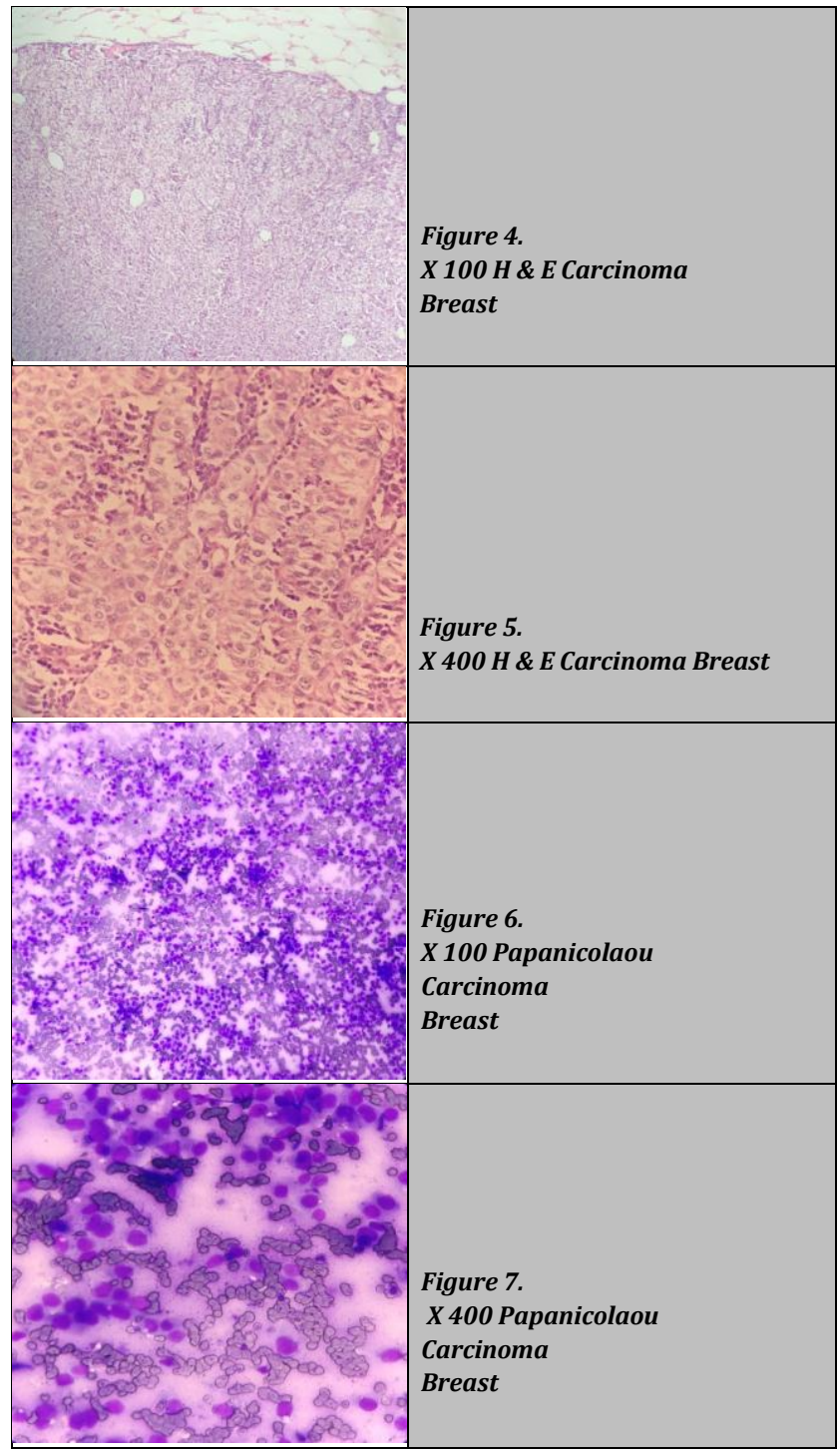

\section{DISCUSSION}

FNAC is one of the most reliable tools for diagnosis of the male breast lesions. It is cost effective, involves minimal discomfort to the patient and can be performed on outpatient basis. All cytological cases were categorized according to IAC dividing all lesions into 5 categories. In this study of male breast lesions, wide age group ranging from 14 years to 81 years was observed. In the present study, $2 \%$ cases were acellular C1. Gynaecomastia C2 was found as the most common male breast lesion (88\%). In a study done by Singh et al. [14] gynaecomastia (84.3\%) was most common male breast lesion. Most of cases of Gynaecomastia were unilateral i.e. 40 out of 44 cases (90.9\%) in present study. While a study done by Westenend et al[7] showed $97.24 \%$ cases of gynaecomastia were unilateral and also, is comparable with the study by Gill et al (79.3\%). [15]

This was also similar to the studies conducted by Das et al. [16] and Martin-Bates et al, [17] who observed it more in the left breast. Only $2 \%$ cases of cytological atypia (category C3) and $2 \%$ cases were suspicious for malignancy (C4 category) were present. Only 1 cases (2\%) of male breast malignancy C5 was noted in the present study which on histopathology confirmed to be IDC breast. While in a study conducted by 
Das et al,[16] prevalence of male breast malignancy were $3.77 \%$, Siddiqui et al,[18] also had $2.8 \%$ of malignant cases which is almost similar to our study whereas Macintosh et $\mathrm{al}^{[1]}$ and Wauters et $\mathrm{al}^{[19]}$ observed $7.9 \%$ and $10.2 \%$ of the cases respectively. In the present study, we had 20\% (10 out of 50) cases with histologic follow-up which is similar to that of a study by MacIntosh et al,[1] (20\%), whereas study by Westend et al[7] observed $47 \%$ and Wauters et al[19] observed (58\%). In present study specificity was $100 \%$. Similar finding noted by Siddiqui et al,[18] and MacIntosh et al.[1] We noticed $100 \%$ sensitivity which is similar to studies like Westend et al[7] \& Wauters et al[19] which showed $100 \%$ sensitivity whereas Siddiqui et al[18] show $95.3 \%$ and MacIntosh et al[1] show $95.5 \%$ sensitivity.

\section{CONCLUSIONS}

Fine-Needle Aspiration Cytology (FNAC) is a good sensitive and specific diagnostic tool for the assessment of breast masses in male patients. Hence, we strongly recommend the use of Fine-Needle Aspiration Cytology (FNAC) as the first line investigation in the clinical evaluation of male breast lumps.

\section{REFERENCES}

[1] MacIntosh RF, Merrimen JL, Barnes PJ. Application of the probabilistic approach to reporting breast fine needle aspiration in males. Acta Cytol 2008;52(5):530-4.

[2] Martin HE, Ellis EB. Biopsy by needle puncture and aspiration. Ann Surg 1930;92(2):169-81.

[3] Singh K, Pinto WRG. A statistical analysis and cytohistologic correlation of fine needle aspiration cytology in lesions of male breast. Ind J Pathol \& Oncol 2015;2(4):215-8.

[4] Crasta JA, Makhija P, Kumar KR, et al. Cytological features of lobular carcinoma of breast: How important are the intracytoplasmic lumina? Indian J Pathol Microbiol 2005;48(2):170-2.

[5] Berner A, Sauer T. Fine-needle aspiration cytology of the breast. Ultrastruct Pathol 2011;35(4):162-7.
[6] Pailoor K, Fernandes H, Jayprakash CS, et al. Fine needle aspiration cytology of male breast lesions- a retrospective study over a six year period. Journal of Clinical and Diagnostic Research 2014;8(10):FC13-5.

[7] Westenend PJ, Jobse C. Evaluation of fine needle aspiration cytology of breast masses in males. Cancer 2002;96(2):101-04.

[8] Bannayan GA, Hajdu SI. Gynecomastia: clinicopathologic study of 351 cases. Am J Clin Pathol 1972;57(4):431-7.

[9] Rudlowski C. Male breast cancer. Breast Care (Basel) 2008;3(3):183-9.

[10] O'Grady WP, McDivitt RW. Breast cancer in a man treated with diethylstilbestrol. Arch Pathol 1969;88(2):162-5.

[11] Singh K, Pinto RGW. A statistical analysis and cytohistologic correlation of fne needle aspiration cytology in lesions of male breast. Indian J Pathol Oncol 2015;2(4):215-8.

[12] Joob B, Wiwanitkit V. Male breast cancer. Ann Afr Med 2017;16(1):37.

[13] Field AS, Raymond WA, Rickard $M$, et al. The International Academy of Cytology Yokohama System for Reporting Breast Fine-Needle Aspiration Biopsy Cytology. Acta Cytologica 2019;63(4):257-73.

[14] Singh R, Anshu, Sharma SM. Spectrum of male breast lesions diagnosed by fine needle aspiration cytology: a 5year experience at a tertiary care rural hospital in central India. Diagn Cytopathol 2012;40(2):113-7.

[15] Gill MS, Kayani N, Khan MN, et al. Breast diseases in males - a morphological review of 150 cases. J Pak Med Assoc 2000;50(6):177-9.

[16] Das DK, Junaid TA, Mathews SB, et al. Fine needle aspiration cytology diagnosis of male breast lesions. A study of 185 cases. Acta Cytol 1995;39(5):870-6.

[17] Martin-Bates E, Krausz T, Phillips I. Evaluation of fine needle aspiration of the male breast for the diagnosis of gynecomastia. Cytopathol 1990;1(2):79-85.

[18] Siddiqui MT, Zakowski MF, Ashfaq R, et al. Breast masses in males: multi-institutional experience on fine needle aspiration. Diagn Cytopathol 2002;26(2):87-91.

[19] Wauters CA, Kooistra BW, Heijden IMK, et al. Is cytology useful in the diagnostic workup of male breast lesions? A retrospective study over a 16-year period and review of the recent literature. Acta Cytol 2010;54(3):259-64. 